Original Research Article

\title{
Analgesic prescribing trends in musculoskeletal disorders
}

\author{
Siddiqui R. A., Shende T. R.*, Shreya Shekhar
}

Department of Pharmacology, NKPSIMS, Nagpur,

Maharashtra, India

Received: 03 July 2018

Accepted: 27 July 2018

\section{*Correspondence to:}

Dr. Shende T. R.,

Email: tanaji.shende@ rediffmail.com

Copyright: (C) the author(s), publisher and licensee Medip Academy. This is an openaccess article distributed under the terms of the Creative Commons Attribution NonCommercial License, which permits unrestricted noncommercial use, distribution, and reproduction in any medium, provided the original work is properly cited.

\begin{abstract}
Background: Musculoskeletal disorders like osteoarthritis, rheumatoid arthritis, bursitis, backache, tendinitis, cervical spondylitis etc. are very commonly encountered in orthopaedic practice and are generally treated with various analgesic drugs. There are number of non-steroidal anti-inflammatory drugs (NSAIDs), opiod analgesics and also fixed dose combination (FDC) of analgesics available for the treatment of such disorders with some advantages and disadvantages of these drugs. Since few studies are there on utilization of analgesic drugs in the orthopaedic practice, this study was undertaken to determine the current prescribing trends for these disorders.

Methods: It was record based observational study carried out at NKP salve institute of medical sciences, Nagpur. A total of 200 prescriptions of patients reported to orthopaedic outpatient department, with presenting complaints of musculoskeletal disorder and rheumatological conditions like osteoarthritis, rheumatoid arthritis, bursitis, backache, tendinitis, cervical spondylitis etc. were noted for the various analgesic drugs prescribed for these disorders.

Results: The common age groups encountered for musculoskeletal disorders were between $41-50$ years $(26 \%)$ and 31-40 years (20\%) followed by other age groups. The common conditions for which patient attended orthopaedic outpatient department were low backpain in $42(21 \%)$ and osteoarthritis in $41(20.5 \%)$ patients followed by others. Aceclofenac and diclofenac were the most commonly prescribed analgesics in $25(12.5 \%)$ and18 (9\%) patients followed by other analgesics. Fixed dose combinations of NSAIDS with other NSAIDS or opoid analgesic were also commonly prescribed. Diclofenac + Paracetamol and Tramadol + Paracetamol were most commonly prescribed combinations in 30 $(15 \%)$ and $19(9.5 \%)$ patients respectively.

Conclusions: As monotherapy aceclofenac and diclofenac were the most commonly prescribed NSAIDS for various musculoskeletal disorders. Also, fixed dose combinations of NSAIDS with other NSAIDS or opoid analgesic were also commonly prescribed. Diclofenac + Paracetamol and Tramadol + Paracetamol were the most commonly prescribed FDCs in our study.
\end{abstract}

Keywords: Fixed dose combination, Non-steroidal anti-inflammatory drugs, Over-the-counter

\section{INTRODUCTION}

Inflammatory disorders, both arthritic and non arthritic, are the most commonly encountered in orthopedic practice, and are generally treated with various non steroidal anti-inflammatory drugs (NSAIDs) with or without additional or specific therapies like steroids, immunomodulators or disease modifying agents. The use of NSAIDs in inflammatory conditions is mainly empirical, as they provide only symptomatic relief without addressing the underlying disease process. NSAIDs also happen to be the most widely prescribed and often misused by self-medication, even for trivial complaints. ${ }^{1}$

NSAIDs are considered as one of the largest groups of pharmaceutical agents. Worldwide, over 30 million people use NSAIDs every day. In the USA alone, the annual number of prescriptions exceeds 111 million. 
Additionally, NSAIDs account for more than $60 \%$ of overthe-counter (OTC) analgesic market. The British National Formulary (BNF) lists more than 20 NSAIDs that are available in at least 40 different formulations. Patients' response to NSAIDs is highly variable. There are several factors that contribute to patients' preference for one drug over another such as treatment efficacy, time and chance to benefit, potential side effects, ease of administration, cost, physician and patient beliefs, drug interaction, severity of disease, and health status. ${ }^{2}$ Despite wide clinical use of classical NSAIDs as analgesics, antipyretics, and anti-inflammatory agents their gastrointestinal toxicity (dyspepsia, peptic ulcers and gastrointestinal bleeds) is a major clinical limitation. ${ }^{3}$

There are a variety of NSAIDs available for prescription: traditional non selective (NSAIDs), and the more selective COX-2 inhibitors (Coxibs). The analgesic effects of the different NSAIDs are more or less identical; however, the Coxibs are associated with a lower risk for upper gastrointestinal side effects. ${ }^{4}$ Tramadol is an opioid analgesic that is frequently prescribed in orthopedics outpatient department (OPD). Tramadol is a synthetic codeine analog, which is a weak $\mu$ opioid receptor agonist. Part of its analgesic effect is produced by inhibition of uptake of norepinephrine and serotonin. In the treatment of mild to moderate pain, tramadol is as effective as morphine or meperidine. Management of pain is important in the majority of the orthopedic conditions like rheumatoid arthritis (RA), osteoarthritis (OA), chronic low back pain (LBP), musculoskeletal pain, etc. Both narcotic and non narcotic analgesics analgesics can be chosen to manage pain. $^{5}$

Periodic Evaluations of drug utilization pattern enable suitable modifications in NSAID prescribing to increase the therapeutic benefit and to minimize the adverse effects. Such studies monitor, evaluate and if necessary, suggest modifications in prescribing behaviours of medical practitioners to make the medical care rational and cost effective. $^{6}$

In developing countries like India, where the financial resources are scarce and affordability of the patients is less, implementation of rational use of medicine (RUM) becomes more important and therefore, the assessment of drug utilization is vital for clinical, economic, and educational purpose. ${ }^{7}$ Studies on the utilization of analgesic drugs in the orthopaedics outpatient department (OPD) are few and therefore this study is undertaken to determine the current prescribing trends in musculoskeletal disorders.

\section{METHODS}

It is unicentric, observational study that was carried out at NKP salve institute of medical sciences and research centre, Nagpur (Maharashtra).
It was conducted in the Orthopaedics OPD of a tertiary care, teaching hospital from October 2017 to March 2018. Ethical committee permission was obtained prior to the study. A total of 200 prescriptions were collected. Prescriptions of patients reported to orthopedic outpatient department, with presenting complaints of musculoskeletal disorder and rheumatological conditions like osteoarthritis, rheumatoid arthritis, bursitis, backache, tendinitis, cervical spondylitis etc. were noted for the various analgesic drugs prescribed for these disorders.

\section{Inclusion criteria}

- $\quad$ Age above 18 years of age

- Both males and females

- Patients who are willing to participate in the study

- Patients treated with oral formulation

- Patients treated with fixed dose combinations.

\section{Exclusion criteria}

- Patients below 18 years of age.

- Patients who are not willing to participate in the study

- Patients with past H/O gastrointestinal diseases

- Patients with past H/O renal disease

- Patients with past H/O liver disease

- Pregnant and lactating patients

- Patients prescribed with NSAIDs in an injectable dosage form

- Patient who was prescribed with Acetylsalicylic Acid (Aspirin) as an antiplatelet medication.

NSAID prescribed as monotherapy or combination therapy and other data will be documented in a specially designed proforma, with following details.

1. Demographic profile: Name, age, gender, and date.

2. Diagnosis for which NSAID is prescribed.

3. Details of NSAID prescription: - Brand/generic name, class, dosage, route, frequency and

4. duration.

5. Type of therapy- monotherapy or combination therapy

\section{Statistical analysis}

Data store, data compilation and statistical analysis were performed in Department of Pharmacology, NKPSIMS, Nagpur. Data was analysed for proportion and the results were described in the form of tables and percentages.

\section{RESULTS}

Authors have studied 200 patients reported to orthopedic outpatient department, with presenting complaints of musculoskeletal disorder and rheumatological conditions.

The most common age group encountered for these disorders is between 41-50 years (26\%) and 31-40 years (20\%) followed by other age groups as shown in Table 1. 
Table 1: Age-wise distribution of patients.

\begin{tabular}{|lll|}
\hline Age range & $\begin{array}{l}\text { No. of patients } \\
(\mathbf{n = 2 0 0 )}\end{array}$ & Percentage $(\%)$ \\
\hline 18-30 years & 29 & 14.5 \\
\hline 31-40 years & 40 & 20 \\
\hline 41-50 years & 52 & 26 \\
\hline 51-60 years & 34 & 17 \\
\hline 51-60 years & 23 & 11.5 \\
\hline $\begin{array}{l}\text { More than } 60 \\
\text { years }\end{array}$ & 22 & 11 \\
\hline
\end{tabular}

The commonest condition for which patient attended orthopaedic outpatient department were low backpain in $42(21 \%)$ and osteoarthritis in $41(20.5 \%)$ patients followed by cervical spondylosis $11.5 \%$, frozen shoulder $7.5 \%$, plantar fasciitis $6.5 \%$, tennis elbow $6 \%$, rotator cuff injury $5.5 \%$, tendintis $5 \%$, synovitis $4.5 \%$, fibromyalgia $4 \%$, ankylosing spondylitis $3 \%$, polyarthralgia $2 \%$, anterior cruciate ligament (ACL) tear $1.5 \%$ and rheumatoid arthritis in $1.5 \%$ of patients as shown in Table 2 .

Table 2: Distribution of illness.

\begin{tabular}{|lll|}
\hline Disease/symptoms & $\begin{array}{l}\text { No. of patients } \\
(\mathbf{n = 2 0 0})\end{array}$ & $\begin{array}{l}\text { Percentage } \\
(\%)\end{array}$ \\
\hline Low back pain & 42 & 21 \\
\hline Osteoarthritis & 41 & 20.5 \\
\hline Cervical spondylosis & 23 & 11.5 \\
\hline Frozen shoulder & 15 & 7.5 \\
\hline Plantar fasciitis & 13 & 6.5 \\
\hline Tennis elbow & 12 & 6 \\
\hline Rotatorcuff injury & 11 & 5.5 \\
\hline Tendinitis & 10 & 5 \\
\hline Synovitis & 9 & 4.5 \\
\hline Fibromyalgia & 8 & 4 \\
\hline $\begin{array}{l}\text { Ankylosing } \\
\text { spondylitis }\end{array}$ & 6 & 3 \\
\hline Polyarthralgia & 4 & 2 \\
\hline $\begin{array}{l}\text { Anterior cruciate } \\
\text { ligament tear }\end{array}$ & 3 & 1.5 \\
\hline Rheumatoid arthritis & 3 & 1.5 \\
\hline Total & 200 & 100 \\
\hline
\end{tabular}

Out of 200 patients 96 patients $(46.5 \%)$ were prescribed single analgesic of which aceclofenac is prescribed to 25 (12.5\%) patients and diclofenac to $18(9 \%)$ followed by etodolac $8.5 \%$, etoricoxib $6.5 \%$, piroxicam $4 \%$, ibuprofen $3.5 \%$ and naproxen in $2.5 \%$ of patients as shown in Table 3.

Fixed dose combination (FDC) of NSAIDS with other NSAIDS or opoid anlgesic or muscle relaxant were prescribed in $107(53.3 \%)$ patients. Diclofenac + Paracetamol and Tramadol + Paracetamol were most commonly prescribed in $30(15 \%)$ and $19(9.5 \%)$ patients followed by others as shown in Table 4.
Table 3: Details of drugs prescribed.

\begin{tabular}{|lll|}
\hline Drug name & $\begin{array}{l}\text { No. of prescriptions } \\
(\mathbf{n = 9 3 )}\end{array}$ & $\begin{array}{l}\text { Percentage } \\
(\%)\end{array}$ \\
\hline Aceclofenac & 25 & 12.5 \\
\hline Diclofenac & 18 & 9 \\
\hline Etodolac & 17 & 8.5 \\
\hline Etoricoxib & 13 & 6.5 \\
\hline Piroxicam & 8 & 4 \\
\hline Ibuprofen & 7 & 3.5 \\
\hline Naproxen & 5 & 2.5 \\
\hline Total & 93 & 46.5 \\
\hline
\end{tabular}

Table 4: Details of FDC.

\begin{tabular}{|lll|}
\hline Drug name & $\begin{array}{l}\text { No. of } \\
\text { prescriptions } \\
(\mathbf{n = 1 0 7 )}\end{array}$ & $\begin{array}{l}\text { Percentage } \\
(\%)\end{array}$ \\
\hline Diclofenac + Paracetamol & 30 & 15 \\
\hline Tramadol + Paracetamol & 19 & 9.5 \\
\hline $\begin{array}{l}\text { Etodolac + } \\
\text { Thiocolchicoside }\end{array}$ & 16 & 8 \\
\hline $\begin{array}{l}\text { Diclofenac + Paracetamol } \\
\text { + Chlorzoxazone }\end{array}$ & 14 & 7 \\
\hline $\begin{array}{l}\text { Etoicoxib + } \\
\text { Thiocolchicoside }\end{array}$ & 11 & 5.5 \\
\hline $\begin{array}{l}\text { Aceclofenac }+ \\
\text { Thiocolchicoside }\end{array}$ & 9 & 4.5 \\
\hline $\begin{array}{l}\text { Aceclofenac }+ \\
\text { Paracetamol }\end{array}$ & 8 & 4 \\
\hline Total & 107 & 53.5 \\
\hline
\end{tabular}

\section{DISCUSSION}

This is a record based observational study. In the present study out of 200 patients attending the outpatient department of orthopaedics who have received analgesics for various complaints of musculoskeletal and rheumatological conditions, the two most common age group of patients were between $41-50$ years $(14.5 \%)$ and $31-40$ years $(20 \%)$ of age range followed by other age groups. In a study of analgesic use at a south Delhi hospital in 300 subjects it was observed that maximum number of patients $83(27.6 \%)$ were in the age range of $31-40$ years followed by $68(22.6 \%)$ patients in the range of $41-50$ years. 8 Also in a study at west Bengal out of 200 new patients who attended orthopaedic OPD, patients between $18-30$ years $(28 \%)$ and $31-40$ years $(26.5 \%)$ attended OPD more frequently than other age groups. ${ }^{9}$ These findings are in accordance with present study.

In an observational study in the year 2013 in 200 orthopaedic OPD patients it was found that low back pain $87(43.5 \%)$, various arthritis and osteoporosis $18(9 \%)$ and cervical spondylosis in $18(9 \%)$ were the common causes to visit orthopaedic OPD.10 In a cross sectional, utnicentric study conducted in the orthopaedics OPD of an urban, tertiary care, teaching hospital showed low back pain $32 \%$, 
cervical spondylosis $14 \%$, and osteoarthritis involving different joints $14.5 \%$ were the common conditions for OPD visit. ${ }^{9}$ In present study also, the common conditions for which patient attended orthopaedic OPD were low backpain $42(21 \%)$ and osteoarthritis in 41 (20.5\%) patients.

In a drug utilization of NSAIDs in selected areas of south Delhi region during the six months study period which included 300 patients in OPD and IPD using NSAIDs, it was observed that aryl acetic acid derivatives (aceclofenac, diclofenac) were the most frequently prescribed drugs category $(52.5 \%)$ followed by paracetamol (26.6\%), ibuprofen (10.5\%), nimesulide $(6.26 \%)$ and lornoxicam $(4 \%) .{ }^{8}$ Also, in a retrospective study of eight months to assess the prescribing pattern of NSAIDs utilized in outpatient department of an orthopedic specialty hospital found that osteoarthritis (40\%) was the most predominant presenting complaint and analgesics like aceclofenac $(24.73 \%)$ and diclofenac $(21.20 \%)$ were most commonly prescribed. ${ }^{3}$ Also in a study to determine the pattern of NSAIDs prescribing for arthritic and non-arthritic conditions in orthopedic OPD found that NSAIDs commonly prescribed were aceclofenac $45 \%$, etodolac $20 \%$ and diclofenac 24\%. ${ }^{6}$ These findings shows that aceclofenac is the most commonly use NSAID followed by diclofenac which is in accordance with our study in which aceclofenac is prescribed to $25(26.8 \%)$ and diclofenac to $18(19.3 \%)$ patients. Aceclofenac is a chemical congener of diclofenac with a better gastric tolerability with longer duration of action. ${ }^{1}$ In present study another commonly prescribed NSAID was etodolac in $18.2 \%$ of patients. It is a moderately selective COX-2 inhibitor with properties similar to diclofenac and at lower doses gastric tolerability is better than older NSAIDS. ${ }^{11}$ Etoricoxib was used in $13.9 \%$ of patients. Selective COX-2 inhibitors continue to be used, but their use has declined probably due to the increased risk of heart attack and stroke associated with etoricoxib and other coxibs. ${ }^{12}$

In present study FDCs were prescribed in $53.5 \%$ of patients and combination of diclofenac with paracetamol and tramadol with paracetamol were most commonly prescribed. In a prospective cross-sectional study which evaluated 324 orthopaedic OPD prescriptions, 33.6\% received combination of analgesics and diclofenac+paracetamol $(37.6 \%)$ followed by tramadol+paracetamol $(22.9 \%)$ were the most commonly prescribed combinations. In a study of prescriptions from the OPD of Orthopedics at Dr. B. R. Ambedkar Medical College of the 300 patients, $227(75.66 \%)$ received FDCs and combination of diclofenac with paracetamol $(27.31 \%)$ was the most commonly prescribed. ${ }^{5}$ These findings are in accordance with our study. In an observational prospective study of prescription patterns of 200 patients for six months duration in 2013 in orthopaedic OPD found that tramadol plus paracetamol fixed drug combinations was more commonly prescribed as compared to other FDCs, which is not in alignment with our study. ${ }^{10}$ Combining two NSAIDs is irrational as the two drugs act on the same pathway and irrational FDCs increase chances of adverse drug effects and drug interactions.

\section{CONCLUSION}

Low backpain and osteoarthritis are the common musculoskeletal disorders for which patient attend orthopaedic OPD. As monotherapy aceclofenac and diclofenac were the most commonly prescribed NSAIDS for these disorders. Fixed dose combinations of NSAIDS with other NSAIDS or opoid anlgesic were also prescribed to many patients. Diclofenac plus paracetamol and tramadol plus paracetamol were the most commonly prescribed combinations in our study.

Funding: No funding sources

Conflict of interest: None declared

Ethical approval: The study was approved by the Institutional Ethics Committee

\section{REFERENCES}

1. Jyothi R, Pallavi D, Pundarikaksha HP, Sridharmurthy JN, Girish K. A study of prescribing pattern of nonsteroidal anti-inflammatory drugs in orthopedic opd at a tertiary care hospital. Nat J Basic Med Sci. 2013;4(1):71-4.

2. Qoul KZ, Thuheerat IN, Ashor NA, Hakuz NM. Prescribing patterns of non-steroidal antiinflammatory drugs in outpatient clinics at royal rehabilitation center in king hussein medical center. Zagazig Uni Med J. 2015 Mar 13;20(5).

3. Mudhaliar MR, Neeruganti S, Yiragamreddy PR, Mude A. Prescribing patterns of non steroidal anti inflammatory drugs (NSAIDs) in out patient department of an orthopedic specialty hospital. J Global Trends Pharm Sci. 2016;7(3):3296-301.

4. Singh V, Yadav P, Deolekar P. Current trends of prescribing patterns of NSAIDs in an orthopaedic OPD in a teaching hospital. Int J Pharm Bio Sci. 2014 April;5(2):486-91.

5. Bhaskar R, Veena DR, Padma L, Kumar PA, Moosaraza S. Prescription pattern of analgesics in orthopedics outpatient department at a tertiary care hospital. Int J Basic Clin Pharmacol. 2017 Jan $21 ; 4(2): 250-3$.

6. Latha RA, Srinivasu K, Naik MAB, Reddy JC. A study of prescribing pattern of non- steroidal anti inflammatory drugs in orthopedic outpatient department at a tertiary care hospital. J Evol Med Dental Sci. 2015;4(4):559-64.

7. Agrawal P, Agrawal VK. Evaluation of analgesics use in orthopedic department at tertiary care hospital in Bareilly, Uttar Pradesh, India. Int J Basic Clin Pharmacol. 2018 Jan 20;5(6):2538-41.

8. Alama N, Bhardwaj A, Tiwari R, Sharma S, Dabas V. Drug utilization pattern of patients using NSAIDS in south Delhi hospital. Int J Pharm Pharm Sci. 2012;4(Suppl 3):703-7. 
9. Dalai CK, Kumar A, Banerjee S. Pattern of drugs use in orthopaedic outpatient department in a tertiary care teaching hospital in West Bengal. Indian $\mathrm{J}$ Basic Applied Med Res. 2017 December;7(1):238-43.

10. Nagla A, Wadagbalkar P, Raipurkar S, Patel P. Prescription pattern study of drugs in Orthopedics Outpatient department (OPD) of a Rural Medical College Hospital and Research centre in MP. Indian J Orthopaed Surg. 2016;2(4):367-71.

11. Tripathi KD. Essentials of medical Pharmacology. Seventh edition, New Delhi Jaypee brothers medical publishers Pvt. Ltd. 2013;204.

12. Brunton LL, Chabner BA, Knollman BC. Goodman and Gilman's The Pharmacological Basis of
Therapeutics. 12 $2^{\text {th }}$ Edition. New York: McGraw-Hill Companies Inc. 2011;501,508,992.

13. Nazrina S, Khan MN, Maruf AA. Prescription of analgesics in orthopaedic outpatient department at a tertiary health care facility. Mediscope. 2017 Oct $22 ; 4(1): 11-7$.

Cite this article as: Siddiqui RA, Shende TR, Shekhar S. Analgesic prescribing trends in musculoskeletal disorders. Int J Basic Clin Pharmacol 2018;7:1782-6. 